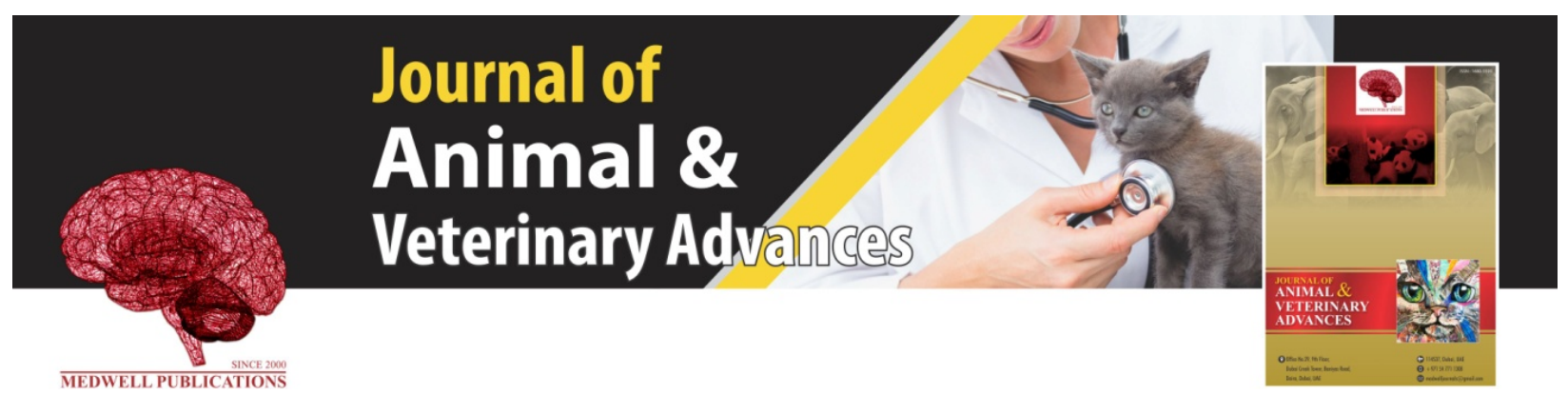

\title{
Husbandry and Breeding Practices of Malle Cattle Reared in Malle District South Omo Zone of Southwest Ethiopia
}

${ }^{1}$ Demerew Getaneh, ${ }^{2}$ Sandip Banerjee and ${ }^{3}$ Mestawet Taye

${ }^{1}$ Department of Animal and Range Sciences, Faculty of Agriculture, Hawassa University, P.O. Box 05 Hawassa, Awasa, Ethiopia

${ }^{2}$ Jinka Agricultural Research Center, P.O. Box 96 Jinka, Ethiopia

${ }^{3}$ Southern Agricultural Research Institute, P.O. Box 06 Hawassa, Ethiopia

Key words: Ethiopia, breeding practices, Malle cattle, production, reproduction traits, South Omo

Corresponding Author:

Demerew Getaneh

Department of Animal and Range Sciences, Faculty of Agriculture, Hawassa University, P.O. Box 05 Hawassa, Awasa, Ethiopia

Page No.: 323-338

Volume: 18, Issue 12, 2019

ISSN: $1680-5593$

Journal of Animal and Veterinary Advances

Copy Right: Medwell Publications
Abstract: Cattle reared at South Omo of Southern Ethiopia play important roles in the livelihood of the people residing in the area. However, due to the remoteness of the area very few scientific studies have taken place and most of the cattle in the region are yet to be studied. The objective of this study was to identify the prevailing cattle production/husbandry practices of Malle cattle. Data were collected through semi-structure questionnaire, field observations and focus group discussions. A total of 360 cattle with different ages were selected randomly from different locations. Data was evaluate using non parametric tests viz. chi-square $\left(\chi^{2}\right)$ and analysed using descriptive statistics. The major feed resource was natural pasture and source of water was from river. Mating was panmictic and the cattle were raised for milk, income, draft power, dowry, besides others. Body size and conformation, coat color and growth rate were criteria in selecting breeding bulls while cows were selected based on their milk yield, coat color and reproductive efficiency. Reported production constraints were feed and water shortage, disease and recurrent drought. The average age at first mating, age at first calving, calving interval and length of dry period of cows were $45.25 \pm 0.87,58.78 \pm 0.73,22.7 \pm 0.63$ and $3.15 \pm 0.13$ months, respectively. The average ages at first mating of bulls' were $46.8 \pm 0.83$ months. Mall cattle showed well adapted under the prevailing harsh environmental conditions. However, communities must be advised on proper rangeland management and improvement measures. 


\section{INTRODUCTION}

Livestock production is one of the primary agrarian activities which directly or indirectly employ a large section of the society, especially, those residing in the rural areas (Zeleke and Melese, 2018; Ayeneshet et al., 2017). Several studies have indicated that the overall productivity of the livestock does not commensurate with their population (Abera, 2018). This may be because of low per unit productivity of the animals themselves and that their management is mostly up to the market (Abera, 2018). Management of the animals should change with the agro climate and the prevailing diseases and parasites (Berhane, 2017). As the agro climate of a region is changing over time and the natural resources are getting strained due to geo political and anthropogenic causes therefore it is imperative to amend the management of the livestock coextensive with the changes (Berhane, 2017). Hence, the overall improvement of the sector can be only through proper management of the animals.

Livestock is the biggest income contributor in pastoral and agro pastoral $(65 \%)$, dairy commercial $(55 \%)$ and urban/peri-urban systems (47\%) (FAO., 2018). Livestock husbandry practices also play important roles in utilization of land and other natural resources which are otherwise unsuitable for any farming activities (Abraham and Hailu, 2018). Almost all the livestock cattle husbandry is the pillar of socio cultural aspects of the traditional society. This is because cattle serve multifarious purposes viz. the bulls as draft animals, cows as a source of milk and calves besides the droppings are used as manure and also beef and skin (Abera, 2018).

The cattle in the country are adapted to varying agro ecologies from the highlands of the country (primarily under mixed livestock farming system) to, the lowlands (where they are raised under extensive/transhumance/ nomadic farming system (FAO., 2018). Cattle adapted to a particular agro climate usually can perform better provided the basic amenities related to the management are made available to them, understanding the agro climate also provides an insight of the realistic developments that can be achieved through crossbreeding programs (Berhane, 2017). Studies by Reta and Abriham (2018) have indicated that in spite of the fact that the population of the cattle are quite high the overall productivity is far below the expectations.

The cattle reared in South Omo zone are known to be one of the small East African zebu (Terefe et al., 2010). These cattle are raised in the tsetse fly infested belt of South Western Ethiopia and are quite tolerant to the parasitic infestation (Terefe et al., 2010). They provide some sort of guarantee for availability of livestock products viz. milk, meat and blood besides also as socio cultural importance. Despite their importance and adaptive capacity (to harsh environment) these indigenous types of cattle are yet to be studied in detail. Thus, the present study was conducted to investigate prevailing cattle production/husbandry practices under which the Malle cattle are reared in Malle District of South Omo zone, Southern Ethiopia.

\section{MATERIALS AND METHODS}

Description of study area: The study was conducted in Malle district South Omo Zone of Southern Ethiopia. The district covers an area of $1432 \mathrm{~km}^{2}$. The population density of the district is very sparse with an estimate of 66 persons per $\mathrm{km}^{2}$. The altitude of the district ranges between 600-1500 masl. The study area is situated between $5.08^{\circ} \mathrm{N}-6.01^{\circ} \mathrm{N}$ latitudinal and $36.3-37^{\circ} \mathrm{E}$ longitudinally. It had comprised $40 \%$ mid-altitude which ranging from 1000-1400 masl land whereas $60 \%$ is lowlands which has been ranging from the 605-999 masl. The mean annual rainfall is ranging from $800-1200 \mathrm{~mm}$ with annual temperature has lain between $18-35^{\circ} \mathrm{C}$.

Site selection and sampling techniques: The identification of cattle owners and kebeles were selected purposively because of they were known to have a reasonably high density of cattle populations, accessible through all weather, road, security concerns and the cooperation of the residents. Before data collection, a questionnaire was prepared in accordance with the objectives of the study. A total of 360 adult cattle (120 bulls and 240 cows) were selected randomly from different locations of study areas for the survey. A total of 120 cattle owners were selected randomly and interviewed by the researcher. The respondents those who owned at least 5 adult cattle and at least 5 years experience in rearing them and willing to participate in the program were purposively identified and from the identified cattle rearers $30 \%$ of them were randomly selected from participant.

Data collection procedures: The study assessment was conducted from December, 2017 to April, 2018 and both primary and secondary data sources were used. Before the actual study, the researcher held short discussions with zone and district agricultural and rural development offices on the importance of the study to identify the study sites based on agro-ecology. Following the selection, primary data were collected by the researcher himself through focus group discussions. Thereafter the key informants were interviewed and recorded through the guidance of the checklist/questionnaire. The secondary data were also accumulated from zonal bureau of agriculture office, official records, books and journals. The questionnaire was pre-tested before the actual administration and some re-arrangement, reframed and 
corrected; this was carried out in accordance with FAO. (2012). A semi-structured questionnaire was administered to the cattle owner in the selected kebeles. The questionnaire focused on socio economic characteristics of the household; major cattle production constraints, diseases challenges and routine husbandry practices of the cattle reared in studied areas, so as to develop future intervention/breeding strategies regarding the same.

Focus group discussion: Focused group discussions were held with elderly farmers, village leaders and ethnically elite farmers who were known to have better knowledge on the present and past social and economic status of the study areas, to substantiate the information collected through individual farmer interview. Information on the existing cattle breed, current status, trait preferences of the farmers, indigenous knowledge on management of breeding and major cattle production constraints were collected. Development agents who are capable of speaking the local language (Malegna) involved in the identification of respondents for the group discussion.

Data management and statistical analysis: The collected data from each studied site was checked for any error and coded and entered into computer for further analysis. Quantitative and qualitative variables measured and collected from field through survey and secondary data sources were summarized and described by descriptive statistics using Statistical Package for Social Sciences (SPSS 14.0 for windows, release 14.0, 2005). The qualitative traits were accessed using non parametric methods (chi square analysis) while the means of the quantitative parameters were accessed using one way ANOVA and the significant means were compared by using Duncan's multiple range test, values were considered significant at $\mathrm{p}<0.05$. An index was calculated as the sum of weighted number of response for criterion to provide overall ranking for qualitative data according to the following formula:

Index $=\Sigma$ of $\left[\mathrm{n}^{*}\right.$ number of response criterion ranked $1 \mathrm{st}+\mathrm{n} *$ number of response ranked $2 \mathrm{nd}+\ldots+1 *$ number of response ranked nth] given for particular qualitative variables divided by the sum of responses under each rank $\Sigma$ of [n-1* total response ranked $1 \mathrm{st}+\mathrm{n}$ $1 *$ total response ranked 2 nd $+\ldots+1 *$ total response ranked nth] for all qualitative variables (criteria) considered. Where $\mathrm{n}$ is the number qualitative trait to be ranked.

\section{RESULTS AND DISCUSSION}

Socio-economic characteristics: The findings indicate that there were no differences in family size among the respondents from the two agro ecologies (Table 1). The study further indicates that most of the respondents were
Table 1: Socio-economic characteristics of the respondents in the study areas $(\%)$

\begin{tabular}{|c|c|c|c|c|}
\hline \multirow[b]{2}{*}{ Descriptors } & \multicolumn{4}{|c|}{ Agro-ecologies } \\
\hline & Midland & Lowland & Overall & $x^{2}$ \\
\hline Sex of respondents & & & & 0.19 \\
\hline Male & 73.3 & 81.7 & 77.5 & \\
\hline Female & 26.7 & 18.3 & 22.5 & \\
\hline Marital status & & & & 0.18 \\
\hline Married & 98.3 & 93.3 & 95.8 & \\
\hline Divorced & 1.7 & 6.7 & 4.2 & \\
\hline Age group (years) & & & & 0.33 \\
\hline$\leq 30$ & 25 & 15 & 20 & \\
\hline $31-60$ & 61.7 & 73.3 & 67.5 & \\
\hline$>60$ & 13.3 & 11.7 & 12.5 & \\
\hline Educational level & & & & 0.13 \\
\hline Illiterate & 58.3 & 78.3 & 68.3 & \\
\hline Read and write & 20 & 10 & 15 & \\
\hline Primary & 15 & 8.3 & 11 & \\
\hline Secondary & 6.7 & 3.3 & 5 & \\
\hline Family size $(m e a n \pm S E)$ & $9.5 \pm 0.50$ & $9.8 \pm 0.48$ & $9.65 \pm 0.49$ & \\
\hline
\end{tabular}

Table 2: Farming activities (\%) and cultivated land holding (ha) in study areas

\begin{tabular}{|c|c|c|c|c|}
\hline \multirow[b]{2}{*}{ Activities } & \multicolumn{4}{|c|}{ Agro-ecologies } \\
\hline & Midland & Lowland & Overall & $\chi^{2}$ \\
\hline Farming activities & & & & $0.006^{* *}$ \\
\hline Crop production & 8.3 & 3.3 & 5.8 & \\
\hline Livestock production & 10 & 33.3 & 21.7 & \\
\hline Both (crop-livestock) & 81.7 & 63.3 & 72.5 & \\
\hline \multicolumn{5}{|c|}{ Land holding/ha. $($ Mean \pm SE) } \\
\hline For crop cultivation & $0.72 \pm 0.05$ & $0.88 \pm 0.078$ & $0.80 \pm 0.047$ & 0.107 \\
\hline For livestock grazing & $0.23 \pm 0.03$ & $0.36 \pm 0.10$ & $0.27 \pm 0.03$ & 0.143 \\
\hline
\end{tabular}

males which were similar across both the studied agro ecologies. Furthermore, most of the respondents were married and belonged to 31-60 age category followed by those who were below 30 years of age. Most of them were illiterate, followed by those who were barely able to read and write.

Production system: The study also indicated that most of the respondents practiced mixed farming across the study areas while they were more dependent on agronomic activities when compared to livestock related activities alone (Table 2). Farming activities between the two agro-ecologies was significantly different $(\mathrm{p}<0.05)$ and in midland crop-production the majority farming activities compared to lowland areas whereas in lowland areas livestock production was the main farming activities than midland areas.

Origin and distribution of Malle cattle: According to the results of the focus group discussion, it was revealed that the Malle cattle were reared for long by their ancestors. They pointed out that the Malle cattle were originated and introduced to the study area from GamoGofa. They were earlier bartered with other 
Table 3: Livestock species (mean \pm SE) of the households

\begin{tabular}{|c|c|c|c|}
\hline \multirow{2}{*}{$\begin{array}{l}\text { Livestock } \\
\text { species }\end{array}$} & \multicolumn{3}{|c|}{ Agro-ecologies } \\
\hline & Midland & Lowland & Overall \\
\hline Cattle & $11.9 \pm 0.8$ & $12.8 \pm 0.9$ & $12.3 \pm 0.6$ \\
\hline Goats & $13.7 \pm 1.16$ & $19.1 \pm 1.96^{*}$ & $16.4 \pm 1.5$ \\
\hline Sheep & $8.6 \pm 1.2 *$ & $4.2 \pm 0.5$ & $7.0 \pm 0.8$ \\
\hline Chicken & $8.2 \pm 0.4^{*}$ & $6.8 \pm 0.4$ & $7.5 \pm 0.4$ \\
\hline Donkey & $1.4 \pm 0.3$ & $1.4 \pm 0.1$ & $1.4 \pm 0.2$ \\
\hline
\end{tabular}

different, $\mathrm{SE}=$ Standard Error

livestock viz. goats. As they were frequently treaded in the study areas, hence, the role of the traders cannot also be ruled out. The study also indicated that some of the key informants associated the name of the cattle with the tribe rearing them. They believed that previously the local chieftain around Malle known as "Maleka" purchased some cattle during his journey from GamoGofa to this area. Thereafter the descendants of the cattle are known as Malle cattle and similar type of cattle are also raised in the neighboring GamoGofa zone and also extends to the nearby districts of Benatsemay, Gidola, Hamer and lowlands of South Omo zone. However, due to lack of historical records the answers could not be compared and hence, the findings are quite debatable.

Livestock composition and holding pattern: The major livestock species observed in the study area were cattle, sheep, goats, poultry and donkey. The result from this study revealed that there were difference $(p<0.05)$ in livestock composition across location (Table 3). The study indicates that the numbers of goats were higher $(p<0.05)$ in the lowlands and while the numbers of sheep and chickens were higher $(p<0.05)$ in the midlands. The study, however, indicated that there was no difference in the numbers of cattle reared in the studied agro ecologies. Furthermore, the study also revealed that the numbers of equines were very few and did not vary across the study areas.

Trend in livestock population: According to the focus group discussions and key informants, the population of Malle cattle is decreasing over the years. This decreasing trend is higher in the midlands when compared to the lowlands due to shrinkage in grazing areas. In both the study areas this was ascribed to both ecological and anthropogenic factors. The global climate change is consider as the one large factor associated with such changes followed by overgrazing leading to soil erosion and degradation.

Purposes of keeping cattle in study area: Cattle are the main assets of the households in the study areas upon which the livelihood of the communities depend on. The dependence are usually both tangible and intangible and the major reason for which the cattle are reared are source
Table 4: Population trends of major livestock species across study areas

\begin{tabular}{|c|c|c|c|c|}
\hline \multirow{2}{*}{$\begin{array}{l}\text { Livestock } \\
\text { species/Trend }\end{array}$} & \multicolumn{4}{|c|}{ Agro-ecologies } \\
\hline & Midland & Lowland & Total & $\chi^{2}$ \\
\hline Cattle & & & & 0.13 \\
\hline Increasing & 0.0 & 5 & 2.5 & \\
\hline Decreasing & 98.3 & 95 & 96.7 & \\
\hline Stable & 1.7 & 0.0 & 0.8 & \\
\hline Sheep & & & & 0.36 \\
\hline Increasing & 1.7 & 5 & 3.3 & \\
\hline Decreasing & 96.7 & 95 & 95.8 & \\
\hline Stable & 1.7 & 0.0 & 0.8 & \\
\hline Goats & & & & 0.35 \\
\hline Increasing & 15 & 11.7 & 13.3 & \\
\hline Decreasing & 83.3 & 81.7 & 82.5 & \\
\hline Stable & 1.7 & 6.7 & 4.2 & \\
\hline Poultry & & & & $0.01^{*}$ \\
\hline Increasing & 55 & 33.3 & 44.2 & \\
\hline Decreasing & 45 & 66.7 & 55.8 & \\
\hline Stable & 0.0 & 0.0 & 0.0 & \\
\hline Donkeys & & & & $0.00^{*}$ \\
\hline Increasing & 4 & 28.3 & 16.7 & \\
\hline Decreasing & 63.3 & 61.7 & 62.5 & \\
\hline Stable & 31.7 & 10 & 20.8 & \\
\hline
\end{tabular}

Table 5: Purpose of keeping cattle in the study district

\begin{tabular}{llll}
\hline Location & Purpose & Index & Rank \\
\hline Midland & Milk & 0.19 & 1st \\
& Income source & 0.17 & 2nd \\
& Draft power & 0.14 & 3rd \\
& Dowry & 0.11 & 4th \\
& Cultural value & 0.11 & 4th \\
& Meat & 0.11 & 4th \\
& Breeding & 0.08 & 5th \\
& Blood & 0.05 & 6th \\
& Hide & 0.04 & 7th \\
& Milk & 0.18 & 1st \\
& Income source & 0.17 & 2nd \\
& Dowry & 0.13 & 3rd \\
& Cultural value & 0.11 & 4th \\
& Meat & 0.11 & 4th \\
& Blood & 0.08 & 6th \\
& Breeding & 0.06 & 7th \\
& Hide & 0.06 & 7th \\
\hline
\end{tabular}

Index $=$ Sum of $(9 *$ for ranked 1 st $+8 *$ for ranked 2 nd $+7 *$ for ranked 3 rd $+6 *$ for ranked 4 th $+5 *$ for ranked 5 th $+4 *$ for ranked 6 th $+3 *$ for ranked $7 \mathrm{th}+2 *$ for ranked $8 \mathrm{th}+1 *$ for ranked 9 th) given for each purpose divided by sum of $\left(9 *\right.$ for ranked $1 \mathrm{st}+8^{*}$ for ranked $2 \mathrm{nd}+7^{*}$ for ranked $3 \mathrm{rd}+6^{*}$ for ranked 4 th $+5 *$ for ranked 5 th $+4 *$ for ranked 6 th $+3 *$ for ranked 7 th $+2 *$ for ranked 8 th $+1 *$ for ranked 9 th) for all purpose of keeping cattle in a study site; $\mathrm{I}=$ Index; $\mathrm{R}=$ Rank

of food, social functions (prestige, dowry and other socio-cultural values), saving, income source and risk minimization. The number of cattle owned correlates with the status of individuals and indicator of wealth in the community. The study further indicates that across both the agro ecologies the cattle play multifarious roles for the society. The reasons being more or less similar across both the agro ecologies, primordially the cattle are raised for milk production followed by income, draft power and dowry in the descending order while the draft power is replaced by dowry and cultural values in the lowlands (Table 4-6). 
J. Anim. Vet. Adv., 18 (12): 323-338, 2019

Table 6: Trait preferences in the study areas

\begin{tabular}{llll}
\hline Location & Traits & Index & Rank \\
\hline Midland & Milk yield potential & 0.23 & 1st \\
& Draftablity & 0.17 & 2nd \\
& Adaptation trait & 0.17 & 2nd \\
& Coat color & 0.17 & 2nd \\
& Reproductive efficiency & 0.1 & 3rd \\
& Temperament & 0.08 & 4 th \\
& Meat yield & 0.08 & 4 th \\
Lowland & Milk yield potential & 0.25 & 1st \\
& Coat color & 0.22 & 2nd \\
& Draftablity & 0.16 & $3 \mathrm{rd}$ \\
& Reproductive efficiency & 0.12 & 4 th \\
& Meat yield & 0.1 & 5th \\
& Temperament & 0.07 & 6 th \\
& Adaptation trait & 0.06 & 7th \\
\hline
\end{tabular}

Table 7: Selection criteria for steers/bulls and heifers/cows in the study area

\begin{tabular}{|c|c|c|c|c|}
\hline \multirow[b]{2}{*}{ Location/Criteria } & \multicolumn{2}{|c|}{ Steers/bulls } & \multicolumn{2}{|c|}{ Heifers/cows } \\
\hline & Index & Rank & Index & Rank \\
\hline \multicolumn{5}{|l|}{ Midland } \\
\hline Body size & 0.23 & $1 \mathrm{st}$ & 0.21 & $1 \mathrm{st}$ \\
\hline Colors & 0.21 & 2nd & 0.18 & 2 nd \\
\hline Horns & 0.08 & 6th & 0.05 & 7th \\
\hline Disease tolerance & 0.07 & 7th & 0.06 & 6th \\
\hline Heat tolerance & 0.04 & 8th & 0.07 & 5 th \\
\hline Temperament & 0.09 & 5 th & 0.08 & 4th \\
\hline Growth rate & 0.17 & $3 \mathrm{rd}$ & 0.15 & $3 \mathrm{rd}$ \\
\hline Fertility & 0.11 & 4th & 0.18 & 2nd \\
\hline \multicolumn{5}{|l|}{ Lowland } \\
\hline Body size & 0.23 & $1 \mathrm{st}$ & 0.19 & $1 \mathrm{st}$ \\
\hline Colors & 0.2 & 2nd & 0.16 & $3 \mathrm{rd}$ \\
\hline Horns & 0.07 & 6th & 0.04 & 7th \\
\hline Disease tolerance & 0.05 & 8th & 0.07 & 6th \\
\hline Heat tolerance & 0.06 & 7th & 0.1 & 4 th \\
\hline Temperament & 0.11 & 4th & 0.08 & 5 th \\
\hline Growth rate & 0.19 & $3 \mathrm{rd}$ & 0.17 & 2 nd \\
\hline Ertility & 0.09 & 5 th & 0.19 & $1 \mathrm{st}$ \\
\hline \multicolumn{5}{|c|}{$\begin{array}{l}\text { Index }=\text { Sum of }\left(8^{*} \text { for ranked } 1 \text { st }+7^{*} \text { for ranked } 2 \text { nd }+6^{*} \text { for ranked }\right. \\
3 \text { rd }+5^{*} \text { for ranked } 4 \text { th }+4^{*} \text { for ranked } 5 \text { th }+3^{*} \text { for ranked } 6 \text { th }+2^{*} \text { for } \\
\left.\text { ranked } 7 \text { th }+1^{*} \text { for ranked } 8 \text { th }\right) \text { given for each selection criteria divided } \\
\text { by sum of }\left(8^{*} \text { for ranked } 1 \mathrm{st}+7^{*} \text { for ranked } 2 \text { nd }+6^{*} \text { for ranked } 3 \text { rd }+5^{*}\right. \\
\text { for ranked } 4 \text { th }+4^{*} \text { for ranked } 5 \text { th }+3^{*} \text { for ranked } 6 \text { th }+2 * \text { for ranked } \\
\left.7 \text { th }+1^{*} \text { for ranked } 8 \text { th }\right) \text { for all selection criteria in a study site. Where } \\
R=\text { Rank; } I=\text { Index }\end{array}$} \\
\hline
\end{tabular}

Trait preferences: Cattle reared in the midlands are selected based on several traits viz. milk yield, followed by draftablity which is correlated with adaptability related traits which is also correlated with coat color while dark coated animals are better adapted in the midlands conversely the light coated animals do well in the lowlands. Draftability too was considered as a trait of importance as well adapted animals will usually be able to perform better and have higher draftablity. The study also indicated that reproductive efficiency of the cattle too was considered as a trait of importance and to certain extent are correlated with their adaptability.

Traditional selection criteria for breeding male and female: The study shows that in both the agro ecologies the bulls are selected based on their body size, followed by their coat colors (Table 7). The bulls with large body
Table 8: Mating system and calving season of Malle cattle (\%)

\begin{tabular}{|c|c|c|c|c|}
\hline \multirow[b]{2}{*}{ Parameters } & \multicolumn{4}{|c|}{ Agro-ecologies } \\
\hline & Midland & Lowland & Overall & $\chi^{2}$ \\
\hline Mating system & & & & 0.20 \\
\hline Random & 91.7 & 90 & 90.8 & \\
\hline Control/hand mating & 5 & 10 & 7.5 & \\
\hline Group mating & 3.3 & 0 & 1.7 & \\
\hline Calving season & & & & $0.00^{* *}$ \\
\hline Short rainy season & 81.7 & 76.7 & 79.2 & \\
\hline Main rainy season & 5 & 21.7 & 13.3 & \\
\hline Dry season & 11.7 & 1.7 & 6.7 & \\
\hline Year round & 1.7 & 0.0 & 0.8 & \\
\hline
\end{tabular}

$* *\left(\chi^{2}<0.01\right)$ the result across the two agro-ecologies significantly different; $\chi^{2}=$ Pearson Chi-square

Table 9: Percentages of households castrate their bull and method of castration $(\%)$

\begin{tabular}{|c|c|c|c|c|}
\hline \multirow[b]{2}{*}{ Parameters } & \multicolumn{4}{|c|}{ Agro-ecologies } \\
\hline & Midland & Lowland & Overall & $\chi^{2}$ \\
\hline$\overline{\text { Do you castrate bull? }}$ & & & & 0.03 \\
\hline Yes & 98.3 & 88.3 & 93.3 & \\
\hline No & 1.7 & 11.7 & 6.7 & \\
\hline Castration methods & & & & 0.13 \\
\hline Traditional & 93.2 & 84.9 & 89.3 & \\
\hline Modern & 6.8 & 15.1 & 10.7 & \\
\hline
\end{tabular}

$\chi^{2}=$ Pearson Chi-square

size are preferred as such animals have high grazing ability and draftablity, besides the same such animals are considered to be attractive and fetch high price. The coat colors of animals are correlated with their adaptability and tolerance to heat and also to a certain extent ecto-parasites. Bulls with higher growth, optimum fertility and good temperament too are preferred. The findings further indicate that the selection of bulls reared in the lowlands too is selected based on similar traits.

The cows reared in the midlands are selected based on their body size across both the agro ecologies. The importance of coat colors too has been reported and the importance is more or less similar to those of the fertility. This too is followed by the temperament of the cattle and their growth. Besides the same in the lowlands the cattle are selected based on their ability to tolerate the hot climate of the region (Table 8).

Mating system and breeding management: The findings show that breeding is panmectica cross the study areas which are also similar to those in other parts of the country. Most of the calving is seasonal which correlates with the advent of the short rainy season when the availability of feed is better than those of the dry season (Table 9).

Castration practices and management: The study pertaining to the castration practices show that castration was carried out among most of the bulls reared across the study locations. Furthermore, the study also indicates that most of the castrations being carried out are traditional in nature (Table 10). 
J. Anim. Vet. Adv., 18 (12): 323-338, 2019

Table 10: Feed resources and feeding practices in Malle district (\%)

\begin{tabular}{|c|c|c|c|c|}
\hline \multirow[b]{2}{*}{ Parameters } & \multicolumn{4}{|c|}{ Agro-ecologies } \\
\hline & Midland & Lowland & Overall & $\chi^{2}$ \\
\hline Sources of feeds in the areas & & & & 0.22 \\
\hline Natural pasture & 63.3 & 70 & 66.7 & \\
\hline Crop residues & 26.7 & 21.7 & 24.1 & \\
\hline Other (different tree branch) & 10 & 8.3 & 9.2 & \\
\hline Grazing methods & & & & $0.00^{* *}$ \\
\hline Herding (communal grazing) & 65 & 100 & 82.5 & \\
\hline Zero grazing (Cut and carry) & 3.3 & 0.0 & 1.7 & \\
\hline Tethering & 31.7 & 0.0 & 15.8 & \\
\hline \multicolumn{5}{|c|}{ Is there seasonal feed shortage? } \\
\hline Yes & 95 & 100 & 97.5 & \\
\hline No & 5 & 0 & 2.5 & \\
\hline Season of feed shortage & & & & $0.04^{*}$ \\
\hline Dry season & 86.7 & 96.7 & 91.7 & \\
\hline Rainy season & 13.3 & 3.3 & 8.3 & \\
\hline
\end{tabular}

Table 11: Water sources and watering frequency both in dry and wet season $(\%)$

\begin{tabular}{|c|c|c|c|c|}
\hline \multirow[b]{2}{*}{ Parameters } & \multicolumn{4}{|c|}{ Agro-ecologies } \\
\hline & Midland & Lowland & Overall & $\chi^{2}$ \\
\hline \multicolumn{4}{|c|}{ Water sources in dry season } & 0.05 \\
\hline Pond/dam & 3.3 & 1.7 & 2.5 & \\
\hline River & 96.7 & 98.3 & 97.5 & \\
\hline \multicolumn{4}{|c|}{ Water sources in wet season } & $0.04^{*}$ \\
\hline Pond/dam & 70 & 85 & 77.5 & \\
\hline River & 30 & 15 & 22.5 & \\
\hline \multicolumn{4}{|c|}{ Watering frequency in dry season } & $0.00^{* *}$ \\
\hline Freely available & 1.7 & 5 & 3.3 & \\
\hline Once a day & 93.3 & 55 & 74.2 & \\
\hline Twice a day & 1.7 & 1.7 & 1.7 & \\
\hline Once in 2 days & 3.3 & 38.3 & 20.8 & \\
\hline \multicolumn{4}{|c|}{ Watering frequency in wet season } & $0.00^{* *}$ \\
\hline Freely available & 75 & 20 & 47.5 & \\
\hline Once a day & 8.3 & 71.3 & 40 & \\
\hline Twice a day & 1.7 & 1.7 & 1.7 & \\
\hline Once in 2 days & 15 & 6.7 & 10.8 & \\
\hline
\end{tabular}

Feed source and feeding practices: Natural pasture followed by crop residues and different tree branch (bush and shrubs) are the major sources of feed in the study areas (Table 11). The study also indicates that the cattle are usually herded together, however, studies also show that tethering too is practiced but limited go the midlands where the agrarian practices predominate. Free grazing is reported to predominate in both the areas while cut and carry system of rearing is mostly observed in the midlands where the cattle are tethered. The shortage of feed is common phenomena during dry seasons like pastoral area of Ethiopia they practice feed conservation methods in some extent through collecting crop residues for further use as mitigation strategies toward feed shortage to the areas. They also reported that, they are not in position of supplementing their livestock with commercial concentrate feeds.
Table 12: Type of cattle housing in the study areas (\%)

\begin{tabular}{lcccc}
\hline & Agro-ecologies & \\
& - & & \\
Parameters & 18.3 & 20 & 19.2 & $0.00^{* *}$ \\
\hline Open camp & 18.3 & 45 & 31.7 & $0.00^{* *}$ \\
Housed at night only & 63.4 & 35 & 49.1 & $0.00^{* *}$ \\
Housed at night and part of the day & 63 & Lowland & --------- \\
\hline The value observed between the & two agro-ecologies & significantly \\
different at ${ }^{* *}\left(\chi^{2}<0.01\right) ; \chi^{2}=$ Pearson Chi-square
\end{tabular}

Table 13: Ranking of disease prevalence among the cattle reared at Malle district

\begin{tabular}{lllll}
\hline & Midland & & \multicolumn{2}{l}{ Lowland } \\
& - & & \\
Diseases & Index & Rank & Index & Rank \\
\hline Anthrax & 0.21 & 3rd & 0.23 & 3rd \\
Blackleg & 0.26 & 1st & 0.26 & 1st \\
Trypanosomasis & 0.25 & 2nd & 0.21 & 4th \\
FMD & 0.12 & 5th & 0.08 & 5th \\
Others* & 0.16 & 4th & 0.24 & 2nd \\
\hline
\end{tabular}

Index $=$ sum of $(5$ for rank $1+4$ for rank $2+3$ for rank $3+2$ for rank $4+1$ for rank 5 ) given for an individual disease divided by the sum of ( 5 for rank $1+4$ for rank $2+3$ for rank $3+2$ for rank $4+1$ for rank 5) for overall disease prevalence. Others* toxic plant, leaf and skin disease and external parasite

Water sources and watering frequency: The results pertaining to the source of water show that the source of water varies across the study areas and also the frequency of watering (Table 12). The source of water in the dry season is mostly from rivers which are there in the areas while water is made available from the ponds/dams and also rivers in the wet season. The frequency of watering too varied across the study areas while the cattle in both the study locations were provided with water once a day during the dry season, however, in many places in the lowlands the cattle are provided with water once every 2 days. During the wet season water is provided adlib in the midlands. The watering frequency in dry and wet season in the two agro-ecologies were different $\left(\mathrm{X}^{2}<0.01\right)$.

Housingpractices: The study shows that across both the study locations the types of housing are more or less similar (Table 13), however, the frequency varied $(p<0.01)$. The study also showed that in the midlands the cattle are housed during the night and part of the day while in the lowlands the cattle are usually housed only during the night hours.

Major disease problems in study areas: The most common diseases across the study areas are blackleg (Table 14). Followed by this the diseases prevalent in the midlands were trypnosomasis while those in the lowlands were prevalence/consumption of toxic plants, skin diseases and also external parasites. This was followed by anthrax which was similar across both the areas. 
Major constraints pertaining to cattle production in the study areas: The most important cattle production constraints across the study areas are summarized in Table 15. The lack of feed, followed by diseases and land shortages were the major constraints facing the respondents from the midlands. The findings from the lowlands indicate that followed by the feed shortages the other constraints include drought which is correlated with water shortages and the prevailing diseases in the study areas.

Reproductive and productive performance of cattle: The average age at first mating of the steers and heifers varied $(\mathrm{p}<0.01)$ across the study areas with values being higher among the heifers and steers raised in the lowlands (Table 15). However, there were no differences across the study areas when it came to traits like average age at first calving, numbers of years the bulls and cows are reproductively active. The numbers of lifetime calving and the average calving interval too did not vary across the study locations. The study also indicates that the average age at castration of the bulls also did not vary among the bulls raised across the study areas while the average working lifespan of the bulls are longer among those reared in the lowlands.

Milk production performance: The findings show the daily milk yield, lactation length and the lactation milk

Table 14: Cattle production constraints as perceived by the respondents

\begin{tabular}{llll}
\hline Location & Constraints & Index & Rank \\
\hline Midland & Feed shortage & 0.29 & $1 \mathrm{st}$ \\
& Diseases & 0.22 & 2nd \\
& Market problem & 0.06 & 6 th \\
& Water shortage & 0.11 & $5 \mathrm{th}$ \\
& Land shortage & 0.17 & $3 \mathrm{rd}$ \\
Lowland & Drought & 0.15 & $4 \mathrm{th}$ \\
& Feed shortage & 0.28 & $1 \mathrm{st}$ \\
& Diseases & 0.20 & $3 \mathrm{rd}$ \\
& Market problem & 0.05 & $6 \mathrm{th}$ \\
& Water shortage & 0.17 & $4 \mathrm{th}$ \\
& Land shortage & 0.08 & $5 \mathrm{th}$ \\
& Drought & 0.21 & $2 \mathrm{nd}$ \\
\hline
\end{tabular}

Index $=$ sum of $(6 *$ for rank $1+5 *$ for rank $2+4 *$ for rank $3+3 *$ for rank $4+2 *$ for rank $5+1 *$ for rank 6$)$ given for each constraint divided by sum of $(6 *$ for rank $1+5 *$ for rank $2+4 *$ for rank $3+3 *$ for rank $4+2 *$ for rank $5+1 *$ for rank 6 ) for all of the constraints for a production system yield across the different parities did not vary across the cows reared in the different agro ecologies (Table 16).

Household characteristics: Most of the respondents were males which can be ascribed to the societal norms where there are restrictions among the female family members to interact with strangers (Zeleka and Melese, 2018; Aman, 2018). The current result was inconsistent with the study of Abera (2018) who had reported that higher numbers of respondents were females in Bishoftu and Asella from Oromia region. However, it creates biasness towards a particular sex and many of the husbandry related practices which are gender specific are not well reflected in the study. Therefore, it is better to include both the sexes in the study to get a proper reflection of the husbandry practices (Worku and Lisanework, 2016). The findings also indicate that most of the respondents belonged to the age group of 31-60 years (Abate et al., 2010; Zeleke and Melese, 2018). The age bracket as indicated show that this is the most productive part of an individual's life as the respondents are both physically able to work for longer hours besides have gained enough experience in agrarian activities and livestock rearing being of no exception (Worku and Lisanework, 2016).

The study also indicates that most of the respondents were not literate and therefore the development agents need to prepare special methods by which scientific livestock husbandry practices can be passed on to the respondents (Ayeneshet et al., 2017; Worku and Lisanework, 2016). Literacy helps in many aspects of scientific studies as it helps in proper recording of production and reproduction traits and thereby better understanding of the economics associated with livestock rearing (Tonamo et al., 2015). Some of the respondents can read and write which too is in close accordance with the findings of Worku (2017).

The family size is quite large when compared to the national average which is in close accordance with the findings of Roberts (2017); Abate et al. (2010); Aman (2018); Olayemi (2012). Small family size helps in appropriate utilization of the meager resources which the agrarian societies usually encounter (Olayemi, 2012).

Table 15: Reproductive and productive performance of cattle in study areas

\begin{tabular}{|c|c|c|c|}
\hline Reproductive parameters & Midland $($ Mean \pm SE) & Lowland (Mean \pm SE) & Overall (Mean \pm SE) \\
\hline Ave age at first mating female (month) & $42.8 \pm 0.87^{\mathrm{b}}$ & $47.7 \pm 1.46^{\mathrm{a}}$ & $45.25 \pm 0.87$ \\
\hline Ave age at first mating male (month) & $42.5 \pm 0.77^{\mathrm{b}}$ & $51.1 \pm 1.25^{\mathrm{a}}$ & $46.8 \pm 0.83$ \\
\hline Ave age at first calving (month) & $59.5 \pm 0.35$ & $58.0 \pm 1.42$ & $58.78 \pm 0.73$ \\
\hline Ave reproductive life time of a cow (year) & $14.88 \pm 0.36$ & $15.73 \pm 0.42$ & $15.3 \pm 0.28$ \\
\hline Ave reproductive lifetime of a bull (year) & $13.5 \pm 0.34$ & $13.9 \pm 0.37$ & $13.7 \pm 0.25$ \\
\hline Number of calving/life time /cow & $7.18 \pm 0.18$ & $7.30 \pm 0.2$ & $7.24 \pm 0.13$ \\
\hline Ave calving interval of cows & $22.4 \pm 0.93$ & $23.0 \pm 0.85$ & $22.7 \pm 0.63$ \\
\hline Ave age of bull castration (year) & $5.44 \pm 0.1$ & $5.6 \pm 0.26$ & $5.51 \pm 0.13$ \\
\hline Ave work life of an ox (year) & $7.80 \pm 0.27$ & $9.01 \pm 0.41$ & $8.40 \pm 0.25$ \\
\hline
\end{tabular}


Table 16: Parity lactation milk yield in Malle cattle (Mean \pm SE)

\begin{tabular}{lllll}
\hline Parity & Variables & Midland & Lowland & Overall \\
\hline First & LL (month) & $8.63 \pm 0.37$ & $7.85 \pm 0.28$ & $8.24 \pm 0.23$ \\
& DMY (L) & $1.46 \pm 0.03$ & $1.36 \pm 0.05$ & $1.41 \pm 0.03$ \\
& LMY (L) & $377.99 \pm 0.34$ & $320.28 \pm 0.42$ & $348.55 \pm 0.2$ \\
Second & LL (month) & $9.66 \pm 0.19$ & $9.63 \pm 0.18$ & $9.65 \pm 0.13$ \\
& DMY (L) & $1.85 \pm 0.07$ & $1.76 \pm 0.04$ & $1.81 \pm 0.04$ \\
& LMY (L) & $536.13 \pm 0.4$ & $508.46 \pm 0.22$ & $523.99 \pm 0.15$ \\
Third & LL (month) & $10.9 \pm 0.15$ & $11.0 \pm 0.13$ & $10.95 \pm 0.10$ \\
& DMY (L) & $1.08 \pm 0.06$ & $0.92 \pm 0.04$ & $1.00 \pm 0.04$ \\
\multirow{5}{*}{ Overall } & LMY (L) & $353.16 \pm 0.27$ & $303.6 \pm 0.16$ & $328.5 \pm 0.12$ \\
& LL (month) & $9.73 \pm 0.23$ & $9.494 \pm 0.197$ & $9.614 \pm 0.154$ \\
& DMY (L) & $1.464 \pm 0.05$ & $1.35 \pm 0.04$ & $1.406 \pm 0.034$ \\
& LMY (L) & $427.34 \pm 0.38$ & $383.65 \pm 0.26$ & $405.5 \pm 0.157$ \\
\hline SE = Standard Error; LL = Lactation Length; DMY= Daily Milk Yield;
\end{tabular}

$\overline{\mathrm{SE}}=$ Standard Error; LL $=$ Lactation Length; DMY = Daily Milk Yield; LMY $=$ Lactation Milk Yield

Large family size usually leads to fragmentation of the land and are usually correlated with illiteracy and poor nutrition and health of the family members (Ayeneshet et al., 2017). On the other hand many members in a family is considered as helpful for the agrarian society as many members can take care of different farm activities and therefore save on labour costs (Olayemi, 2012).

Livestock production system: Most respondents followed mixed farming system and crop and livestock husbandry complement each other which too are in close accordance with the findings of Areb et al. (2017). The study also indicates that the waste product of crop husbandry is also the feed input for the livestock and also the waste from the livestock can be used as an input for the agricultural activities (Kugonza et al., 2011). The land holdings did not vary across the study areas and the land holding are lower than those reported by Kebede et al. (2017) while the land holdings as observed are higher than those reported by Asmare (2018). Fragmentation of land is a great concern among the small holder farmers in the country (Alemu et al., 2017). This along with large family size in one hand is leading to poverty among the agrarian communities as the per capita income is decreasing and the overgrazing of the livestock in the marginal grazing lands is leading to soil erosion and also to some extent bush encroachment and also growth of invasive species (Li et al., 2011; Tilahun et al., 2017; Makkar et al., 2018). The grazing land is also shrinking over time and therefore, the respondents need to be trained in methods by which they can conserve the feed resources and also proper utilization of agricultural by-products and also poor quality feed stuffs such as straw and stovers (Fenetahun et al., 2019; Makkar et al., 2018). If this is not carried out there are chances that the livestock will remain underfed and unproductive. This usually leads to high incidences of diseases and therefore, the overall benefit of the livestock enterprise is at doubt. As the grazing land is shrinking over the period of time the respondents need to be appraised about the benefits of rotational grazing and also inclusion of fodder trees (Tilahun et al., 2017).
Livestock possessions and herd demography: The goat population is higher in the lowlands than midland. This may be ascribed to the adaptability of the goats to the warm agro climate of the region and as the agriculture is sparse in the region and there are large tracts where the animals can graze which too are in close accordance with the findings of Mekete (2016), Abraha (2016). The population of cattle followed of the goats which may be ascribed to the cultural reasons and the cattle play diverse roles in the livelihood of the rearers (Terefa et al., 2015). While, the steers and bulls are used as beasts of burden and are used for various agricultural activities. The cows are basically reared as the mother of the bulls and the extra milk are used for home consumption or are processed into dairy products (Redda, 2001). The culled cows and bulls are then sold for beef and income generating purposes. The study also shows that the numbers of sheep are higher in the midlands as the climate of the region is favorable for the sheep in the region (Abraha, 2016; Aman, 2018). The population of the chickens too varied across the study areas, the numbers being fewer in the lowlands. This may be ascribed to more numbers of predators in the lowlands (Waktole et al., 2018) and also that there are higher incidences of diseases and parasites in the lowlands.

Reason of keeping malle cattle: The most households in the studied district rear cattle for purpose of milk production and income generation. Milk is quite important among the respondents from the lowlands (Worku, 2017). It has also been reported that the milk is processed into butter, cottage cheese etc. This helps in generation of income in the family and also escalates rural employment opportunities (Redda, 2001). Rearing of cattle is also important among the respondents where most of the agrarian activities exist as the bulls are used for traction and the dung is important farm inputs (Tulu et al., 2018). The bullocks are used for draft purposes and the cows as bull mother (Tewelde et al., 2017). However, in the lowlands where the agricultural activities are less the cattle are generally considered as a source of wealth and social pride and are often given off in dowry (Terefe et al., 2015). Cattle as a source of meat, blood and hide are important components for rearing cattle but are ranked lower than what was reported from many other studies (Worku, 2017). This may be because meat from the small ruminants are more important than those of the cattle because of lack of storage facilities and fragmentation of family where carcass of bovines are usually shared among family members and friends (Terefe et al., 2010). The importance of rearing of cattle for hide purpose is of low priority because of lack of processing facilities and also that there are many cheaper substitutes available for the same (Gebrehiwot, 2017). 
Trait preferences: The potential of a cow as a bull mother depends on her lactal yield as a cow with optimum lactal yield is expected to wean heavier calves which can mature early (Taye, 2005). The lactation yield is also important as some extra milk can be used by the rearers themselves and hence, helps in culinary requirements (Garoma et al., 2013). Besides the same milk is a whole some food for the infants, nursing mothers old and infirm (Solomon and Hussen, 2018). The bulls are preferred based on their draftablity. The adaptation of the cattle are also considered as an important criteria for selection, as well adapted cattle are able to tolerate the prevailing diseases and parasites (Terefe et al., 2015). Adaptation to the prevailing agro climate of the region is also important when there are seasonal shortages of feed/fodder and also water (Zewdu et al., 2018). Livestock which are well adapted are able to survive better under the prevailing tropical climate where survivability of the livestock itself is a challenge (Taye, 2005). The cattle in the lowlands are also preferred for their lactal yield which is because milk is one of the most important dietary requirements for the respondents themselves (Redda, 2001). Cattle are also selected based on their coat color which is also important both culturally and in the adaptation point of view (Garoma et al., 2013). Studies by Terefe et al. (2010) have indicated that the respondents from the lowlands prefer to rear cattle with light coat color which helps in adaptation of the cattle to the agro ecology. The respondents in the lowlands also indicated that they prefer to select the cattle based on their draftablity which may also be correlated with their ability to trek for long distances, especially, during the hot season when the vegetation is sparse in the region (Kebede et al., 2017).

Selection criteria of breeding cattle: The traditional selection criteria for the bullswere its body size which is correlated with their muscularity and also draftablity which is in consonance with the findings of Aman (2018) and Abraha (2016). Many traits such as growth, fertility and longevity are significantly important for beef production (Chamberlain, 2017). The bulls which have large body size are also expected to have a good draftablity and also have higher economic value (Tewelde et al., 2017). In addition, the size is directly related to the body structure, harmony and balance of the animals, together with other physiological characteristics, act directly on the mechanisms for adaptation to the environment (Cerqueira et al., 2013). The growth rate of the bulls indicates that the bulls mature early and can be used for draftablity at an early age and hence are more economical when compared to their slow growing counterparts (Zewdu et al., 2018). The coat color of the bulls is also important criteria for selecting the bulls which may be ascribed to their socio cultural preferences and also economic values. It has been reported in a study by Peters et al. (1982) that bulls with light coat color do well in the lowlands as it's associated with their adaptability. The presence of horns in the bulls is also correlated with their masculinity and ability to defend themselves from predators (Tewelde et al., 2017; Garoma, 2006). This trait can also be considered important when it comes to socio cultural values and in many societies bulls with long horns are considered as beautiful (Dioli, 2018).

The findings pertaining to the selection criteria of the cows show that body size is considered as an important trait in both the study locations. This may be ascribed to the fact that large cows are able to trek for longer distances (Minuye et al., 2018). Such cows usually have adequate uterine space and can bear long and strong calves which are correlated with their survivability. Fertility of the cows is an important traits for their selection as fertile cows are expected to bear calves on a regular basis are therefore, economical for the rearers (Garoma et al., 2013). The growth of the cows are also considered as a trait of paramount importance as cows which grow fast are able to attain sexual maturity earlier and also have higher feed conversion efficiency. The findings also indicate that coat color of the cows are important in selection as cows which have lighter coat color are able to survive the warm climate of the lowlands better than their darker coated counterparts, such cows suffer less due to environmental stress and are more productive and fertile (Tewelde et al., 2017). Cows which are well adapted to particular agro ecology usually are healthier (fall sick less often) and are more economical (Solomon and Hussen, 2018).

Mating system and breeding management: Most of the breeding is panmictic. Panmixia in classical terms is helpful in lower inbreeding in the herd as every individual has equal chances of mating with its opposite sex (Nazokkarmaher, 2016). However, in small herds panmixia can lead to higher incidences of inbreeding as there are limited choices among the herd mates. Therefore, the respondents need to be made aware of the ill effects of inbreeding and hence how to avoid such situations (Gebissa, 2014). The respondents also are need to be made aware of the benefits of bull transfer across the district where one bull is not allowed to mate for more than two consecutive seasons in a particular herd (Nazokkarmaher, 2016).

The study also indicates that breeding is seasonal and most of the breeding takes place in the short rainy season which is after the long spell of the dry season (Gebissa, 2014). The season is also correlated with the growth of grasses and forage which leads to build up of body reserves much needed for the growth of the fetus. It has also been reported that on any cases when the cattle are 
stressed there can be cession of estrus cycle or incidences of silent heat which resumes with the availability of the nutrients (Wondossen et al., 2018). Mating during the short rainy season is correlated with calving at the end of the long rainy season by the time when the pregnant cow has amassed enough nutrients, so as to bear the stress associated with the parturition and the lactation yield is also optimized (Cherkoes and Mekuria, 2018). The findings also show that at many cases the calving in the lowlands occur during the long rainy season. However, calving which occur during the long rainy season has several disadvantages as there are more vector borne diseases during the rainy season and that the dampness may result in several diseases to occur (Ayeneshet et al., 2017). Besides the same the cows may not be able to go for grazing due to heavy rains and the only option to feed such cows is through cut and carries system (Terefe et al., 2010).

Castration practices and management: The castration of the bulls was practiced by many of the respondents. Castration is one of the important farm activities which are responsible for prevention of unwanted mating and also helpful in selection (Zedwu et al., 2018). The castrated bulls are usually used for fattening and hence demand higher price (Terefe et al., 2010; Aman, 2018), it also helps in subduing the temperament of the bulls as castrates are easier to handle (Dioli, 2018). However, the age of castration as indicated by the respondents are quite high and thus the castrate may have been sexually active and defies the reason for selection of the bulls as mentioned ahead (Worku, 2017). Therefore, the respondents need to be made aware of identifying good bulls and selecting them at a younger age. Most of the respondents indicated that castration is usually carried out using traditional methods and equipment which too are in close accordance with the findings of Dioli (2018), Abraha (2016). Use of the traditional methods is not only against the livestock welfare as such animals are prone to infections due to the trauma associated with such methods (Roberts, 2017). Therefore, the respondents need to be appraised about the use of modern methods of castration, aftercare associated with castration which includes their feeding and management.

Feed and feeding practices: The results associated with feeding indicated that natural pasture predominate in the study areas which is also in close accordance with the findings of Makkar et al. (2018). However, in most of the studies it has been reported that natural pastures predominate as source of feed (Negash, 2018; Terefe et al., 2015), consecutively it has also been reported that the quality of the pastures have been deteriorating over time. This can be ascribed to overgrazing, bush encroachments and other anthropogenic factors (Khatri and Tyagi, 2015). This situation is also observed in the study location and therefore, the respondents need to be appraised about the methods to prevent land degradation and improve/maintain the quality of the pasture (Tilahun et al., 2017). In addition, rotational grazing is better than continues grazing to improve grazing pasture in terms of quality and quantity. However, zero grazing practice will increase productivity relative to rotational grazing (Ayeneshet et al., 2017). The use of agricultural byproducts as livestock feed has also been reported in several studies (Negash, 2018). However, in most of the cases the agricultural byproducts (straws and stovers) have very poor nutritive values and hence the usages of the same may not be enough even to maintain the body mass. Therefore, the respondents need to be appraising about the methods to improve the feeding quality of the same using urea treatment or other such allied treatment methods (Makkar et al., 2018; Ali et al., 2009). The feeding of tree leaves to the livestock has also been reported by Terefe et al. (2015). These trees serve as fodder, especially, during the dry season. These trees are usually perineal and hence have multipurpose usages (Abate et al., 2010). However, care has to be taken when the leaves are fed in excess as some of the leaves have several anti-nutritional factors (tannins, saponins etc.) which can have adverse effects on the physiology of the livestock (Girmay and Tishome, 2017). Therefore, the respondents need to be appraised about the methods to do away with the same by using several simple and hands on techniques (soaking the leaves in water and other similar methods).

The study further indicates that most of the cattle are herded together (irrespective of the study locations) which too is in close accordance with the studies of Aman (2018). Herding together has several advantages as it requires less labour and provides security to the cows and the calves alike (Roberts, 2017). However, this too leads to overgrazing and also at times there may be fights among the bulls, especially in the breeding season. Therefore, it is advisable to divide the herd into different sexes and also age categories (within sexes), so that, the grazing management can be appropriate (Fenetahun et al., 2019).

Water sources and watering frequency: The sources of water for the livestock are predominantly river followed by ponds and water in the catchments (dams). These observations are in close accordance with the findings of Asmare (2018), Mekete (2016), Ayeneshet et al. (2017). However, the respondents need to be careful when they are taking the livestock to the rivers as there may be aquatic animals and insects viz leeches which can harm them (Tulu et al., 2018) and also there may be improperly disposed carcass from upstream which may harbor many diseases and therefore, the area where the livestock are allowed to drink water need to be kept always clean and free from contamination (Legesse, 2016). The respondents also indicated that ponds are also used as a source of water for the livestock. However, there have been reports 
where the water from the ponds and catchment areas to get contaminated from agricultural runoffs and also anthropogenic usages (Khatri and Tyagi, 2015). Water is one of the vital nutrients needed for many physiological and biochemical activities (Zeleke and Getachew, 2017). However, the quality of water needs to be monitored on a regular basis as there may be runoffs from agricultural activities and also from allied anthropogenic activities (Khatri and Tyagi, 2015).

The results pertaining to the frequency of watering indicate that most of the respondents provide water to their livestock once a day which may always not be enough for the livestock especially in the dry season (Mekete, 2016). If possible the water need to be provided adlib for the livestock as this would be helpful in maintaining the physiological processes besides also be helpful in maintaining the homeostasis of the livestock, especially in the hot season (Ayeneshet et al., 2017). The study also indicates that during the wet season the watering frequency also was mostly once a day in the lowlands whiles it was provided adlib in the midlands which too is in close accordance with the findings of Tonamo et al. (2015). It is therefore, important for the respondents in the lowlands to be taught methods to conserve rain water, so that, the livestock are not deprived of the vital nutrient (Yosef and Asmamaw, 2015).

Housing system in study areas: Housing of livestock is one of the primordial features pertaining to good husbandry practices (Aman, 2018). Proper housing not only assists the livestock but also overcome the vagaries of nature and protects them against the predators and thieves (Ayeneshet et al., 2017). A proper house should be well ventilated and also drain well (Legesse, 2016). The cattle should be housed alone from other livestock and animals of different ages and sexes should not be housed together (Aman, 2018). This can lead to fighting's among the different sexes and may also result in mortalities. The study indicates that most of the cattle in the lowlands are housed only in the nights which too are in close accordance with the findings of Kebede et al. (2017), the observations is however different than those reported by Gebreyohanes (2015) who reported that the cattle in the lowlands are housed in the kraal's which however provides limited protection against the natural calamities and the predators alike. The cattle in the midlands are housed in the night and also during the day when the weather is unfavorable.

Major cattle disease: The most important diseases in the areas were blackleg followed by anthrax which is both vaccine preventable diseases the observations are in close accordance with the findings of Terefe et al. (2015), Tulu et al. (2018), Worku (2017); Ayeneshet et al. (2017). As indicated ahead the respondents need to be made aware of the symptoms associated with the diseases and regular vaccination need to be carried out (Abera, 2018). The respondents need to be appraised about the methods of proper disposal of the carcass, so that, the spread of the disease can be arrested and also that the predators are not attracted to the vicinity of the kebeles (Baba et al., 2017). Deep burial and if possible burning of the carcass need to be advocated using appropriate scientific technologies (Baba et al., 2017). Overgrazing and bush encroachments usually accompany the establishment of poisonous plants/ trees (Worku and Lisanework, 2016). There are several such trees in the Southern region of the country and hence, the respondents need to be appraised about the methods to identify and how to eradicate those (Abera et al., 2014).

Many of these plants are endemic of the region and some of them are introduced over the time and the respondents may not be aware of the same. The other problems may be associated with the endo and ecto parasites which abound the lowlands of the country (Tulu et al., 2018). These parasites not only make the animals weak but are also responsible for the spread of many diseases (Eticha and Disassa, 2017). Therefore, the usages of locally available medicaments (ethno veterinary) need to be identified and the dosages standardized, so that, the respondents are not dependent on acaricides and dewormers which can contaminate the water bodies and the animals develop tolerance towards the same (Minuye et al., 2018).

Cattle production constraints: The study shows that the major constraints in the midland were feed shortages. Feed constraints lead to delay in puberty and thereafter adversely influence the production and reproduction capability of the cattle which are also in close accordance with the findings of Aman (2018), Worku (2017), Abera (2018) as indicated ahead the respondents need to be taught about the methods associated with improving the nutritive value of the crop residues, besides follow rotational grazing and allied techniques, so that, overgrazing and land degradation can be arrested (Fenetahun et al., 2019). The prevalence of diseases too adversely affects the economics of livestock production as diseases not only affect the animals but also cause emotional trauma to the owners (Tulu et al., 2018). However, studies by Tadege and Afera (2016) have indicated that many of the diseases are vaccine preventable and hence, the respondents and the authorities in the study area need to ensure regular vaccination of all livestock.

\section{Reproductive characteristics}

Age at First Mating (AFM): The average age at first mating (service) for the heifers was close accordance with Garoma (2006). The average Age at First Mating (AFM) for the heifers and steers were lower than for Bonga cattle 
reported by Areb et al. (2017). However, the values as observed in this study are considerably $>41$ and 36 months for heifers and steers of Gamo Gofa cattle (Kebede et al., 2017); 35.5 months for Begait heifers (Gebreyohanes, 2015); 44.76 and 41.64 months for Horro heifers; 43.5 and 40.2 months for Arsi heifers and steers (Aman, 2018), respectively. Moreover, Malle cow showed delayed age at first mating compared to other cattle it may be due to poor nutrition associated with prolonged dry season. This may also be a nature of the breed as a whole and as the trait is lowly heritable it can be improved slightly through selection. This trait, however has a serious implication on the overall economics of the cattle husbandry as it will adversely influence the lifetime productivity of the cattle.

Age at First Calving (AFC): The Age at First Calving (AFC) of the Malle cows as recorded in this study was higher than those reported by Terefe et al. (2015) 55.2 months for Mursi cow; 56.4 months (Kebede et al., 2017) for Gamo Gofa cows and 50.8 months (Tewelde et al., 2017) for Begait cow. In spite of this, Mallecow heifers had lower AFC compared to 59.52 months (Areb et al., 2017) for Bonga cow and 59.76 months for Horrocow. This trait is direct fallout of the longer age at first service as reported ahead (Watanabe et al., 2017). This trait too is lowly heritable and can be to a certain extent improved through management of the animals themselves besides the nutrition received (Getinet et al., 2009). The trait can also be influenced by diseases which may lead to abortions and allied causes (Watanabe et al., 2017). The overall economic implication of the trait too has been considered as adverse on the lifetime productivity of the cattle (Ayeneshet et al., 2018). AFC influenced by management and other environmental factors, especially, the plane of nutrition which could determine pre-pubertal growth rates, reproductive organ development and onset of puberty and subsequent fertility (Wondossen et al., 2018).

Calving Interval (CI): Calving Interval (CI) in this study was close accordance with the finding of Ayeneshet et al. (2018) for cattle reared at North Gondar zone of Amhara region. The CI extensively/probably is the best index of cattle herds of reproductive efficiency (Zewde et al., 2018). The overall average calving interval of Malle cattle as recorded in this study was higher than 22.56 months for Horro breed; 14.5 months for Mursibreed (Terefe et al., 2015); 21.24 months for Bonga cow (Areb et al., 2017) and 17.06 months for Begait cow (Gebreyohanes, 2015). Long days opened and prolonged calving interval may affect the overall the revenues of the dairy herd (Watanabe et al., 2017). The longer calving interval too adversely influence the overall economics of cattle husbandry (Ayeneshet et al., 2018) and may be influenced by several factors viz. maternal instinct (Cherkoes and Mekuria, 2018). Inadequate body reserve leading to delay in return of estrus besides there are several diseases which can lead to prolonging of the trait which also has a serious economic implication (Zewdu et al., 2018). Therefore, the management of the cattle has to be done in such a way that the animals are free from any diseases and is properly nourished. For longer CI could be due to poor oestrous detection, silent heats, poor feed quality and health care and poor management.

\section{Productive characteristics}

Calf-crop and reproductive lifetime of bull and cow: The average numbers of calves born and the overall reproductive life of the cattle as indicated in this study are higher than those reported by Dereje for Horro cows (5.92 calves with 11.95 years reproductive life); Kebede et al. (2017) for cows reared at Gamo Gofa (8.8 calves and 10.9 years reproductive lifetime). However, the average numbers of calves born per reproductive lifetime of cows reared at Ogaden is (2.17 calves), however, lower than those reported in the present study (Getinet et al., 2009). The numbers of calves born from Mallecows (7.24 calves), however, lower than Mursi cattle (11 calves) (Terefe et al., 2015) and Bonga cows (9.39 calves with 16.05 years of reproductive lifetime) (Areb et al., 2017).

The average reproductive lifetime of a bull as recorded in the present study was lower than the Mursi bulls (Terefe et al., 2015) but higher than Horro bull. The average calf crop has an economic implication as more numbers of calves born lead way for selecting the replacement for the bulls and the cow's alike (Laske et al., 2012). Higher numbers of calves born also are correlated with the numbers of lactation and also the average milk yield which also has an economic implication (Mathews et al., 2001; Terefe et al., 2010). However, it's not the numbers of calves born that matter but the numbers of calves weaned and those survive their breeding age (Laske et al., 2012). Thus, it's important to ensure the survival of the calves, so that, the overall profitability of the venture is realized and also that appropriate selection is possible from the calves (survived) (Mathews et al., 2001).

Milk production performance: The average Daily Milk Yield (DMY) and Lactation Length (LL) reported in the present study was similar to those reported by Dereje for Horro cattle. However, the present finding was higher than the DMY (1.37 L) and LL (6 month) at the national levels CSA. (2017). The present finding too lower than those of the Nuer cows $(2.9 \mathrm{~L} /$ day $)$ those reported by Minuye et al. (2018). The overall LMY in the present study $(405.5 \mathrm{~L})$ was however, lower than reported by Aman (2018) in Arsi cattle (478.1 L); Tewelde et al. 
(2017) in Begait cow (459.52 L) and Taye (2005) in Sheko cow (698.3 L) but higher than reported by Dereje for Horro cow (394.05 L). The average LMY in midland areas was higher $(427.34 \mathrm{~L})$ than lowland areas (383.65 L). This difference might be due to adverse environmental factors in the lowland areas where the seasonal shortages of feed/fodder, water and high disease prevalence. The overall LMY as reported in this study is actually the off take by the farmers after the suckling of the calves. Therefore, there is a scope of improving the trait among the cattle included in the study; this can be carried out through within breed selection and also their management.

\section{CONCLUSION}

This study was conducted to assess the prevailing cattle production/husbandry practices. The herd structure values indicated that the numbers of cows were the highest amongst all classes of cattle. This was primarily because they are/were the progenitors of the replacement stock. Besides nursing the calves the extra milk was used for household consumption and also for the production of butter and other allied dairy products. These cattle are used for multifarious multi-purposes animal's viz. milk production, draft power, sources of cash and social functions. However, the functions played by the cattle tend to differ in importance between locations. However, the priorities vary across the locations viz. milk production and cultural values are more important in the lowlands. Contrarily milk production and draft power are more important in midland areas. The bulls and cows are selected based on their physical appearance (coat color, horn, tail and growth rate and disease/heat tolerance) and body size conformation (height and length) while the production and reproduction traits take a backstage. Mating is panmectic. The average AFM, AFC and CI of cows were $45.25 \pm 0.87,58.78 \pm 0.73$ and $22.7 \pm 0.63$ months, respectively. These cattle are well adapted to the agro ecology of the area and are well tolerant to common diseases and can live off the land, especially when the forage and water is wanting.

\section{RECOMMENDATIONS}

There is high movement of cattle in the area hence there are chances of crossbreeding, thus, conservation efforts need to be strengthened; an efficient animal health services: is a prerequisite for rational animal production. Therefore, appropriate disease prevention and control programmes are essential to reduce the overall morbidity and mortality of animals. Moreover, periodic vaccination program and good husbandry practices shall be practiced. For implementation, government should provide more veterinary facilities to minimize this incidence of diseases and parasites. The communities must be advised on proper rangeland management and improvement measures or practices (rotational grazing, reduce overgrazing and land degradation).

\section{ACKNOWLEDGEMENTS}

This study was made possible with funding from Southern Agricultural Research Institute (SARI). Researchers are extremely thankful the SARI and also Jinka Agricultural Research Center for providing logistical support.

\section{REFERENCES}

Abate, T., A. Ebro and L. Nigatu, 2010. Traditional rangeland resource utilization practices and pastoralists perceptions on land degradation in South-East Ethiopia. Trop. Grassland., 44: 202-212.

Abera, D., T. Jibat, T. Sori, A. Feyisa and T. Beyene, 2014. Assessment of plant and chemical poisoning in livestock in central Ethiopia. J. Environ. Anal. Toxicol., Vol. 4, No. 3. 10.4172/2161-0525.1000215

Abera, J., 2018. Assessment of resilience of dairy farming in bishoftu and Asella areas, Oromia regional state, Ethiopia. M.Sc. Thesis, Addis Ababa University, Ethiopa.

Abraha, F., 2016. Indigenous livestock husbandry and ethno veterinary practices in Endamohoni District of Tigray Region, Ethiopia. M.Sc. Thesis, Hawassa University, Hawassa, Ethiopia.

Abraham, A. and A. Hailu 2018. Ethiopian indigenous cattle breed's diversity, distribution, purpose of keeping and their potential threats. J. Bio. Innov., 7: 770-789.

Alemu, G.T., Z.B. Ayele and A.A. Berhanu, 2017. Effects of land fragmentation on productivity in northwestern Ethiopia. Adv. Agric., Vol. 2017. 10.1155/2017/4509605

Ali, I., J.P. Fontenot and V.G. Allen, 2009. Palatability and dry matter intake by sheep fed corn stover treated with different nitrogen sources. Pak. Vet. J., 29: 199-201.

Aman, G., 2018. Studies on structural, functional traits and traditional breeding practices of Arsi cattle in East Showa and West Arsi Zone of Oromia Reginal State Ethiopia. M.Sc. Thesis, College of Agriculture, Hawassa University, Ethiopia.

Areb, E., T.G. Silase, D.H. Giorgis, C. Reti, B. Zeleke and M. Mamiru, 2017. Phenotypic characterization and production system of Bonga cattle in its production environment of Kaffa Zone, Southwest Ethiopia. Sky J. Agric. Res., 6: 62-72.

Asmare, B., 2018. Smallholder farmers livestock production and marketing in Bahir Dar Zuria District, Northwestern Ethiopia. J. Dev. Agric. Econom., 10: 159-164. 
Ayeneshet, B., Z. Wondifraw and M. Abera, 2017. Survey on farmers husbandry practice for dairy cows in Alefa and Quara Districts of North Gondar Zone, Amhara national regional state, Ethiopia. Survey on farmers husbandry practice for dairy cows in Alefa and Quara Districts of North Gondar Zone, Amhara national regional state, Ethiopia. 10.13140/RG.2.2.28197.76006

Ayeneshet, B., Z. Wondifraw and M. Abera, 2018. Reproductive and productive performance of indigenous dairy cows under smallholder farmers management system in North Gondar Zone, Ethiopia. J. Fisheries Livest. Prod., Vol. 6, No. 1. 10.4172/2332-2608.1000261

Baba, I.A., M.T. Banday, A.A. Khan, H.M. Khan and N. Nighat, 2017. Traditional methods of carcass disposal: A review. J. Dairy Vet. Anim. Res., 5: 21-27.

Berhane, H., 2017. Ethiopian cattle genetic resource and unique characteristics under a rapidly changing production environment-A review. Int. J. Sci. Res. (IJSR), 6: 1959-1968.

CSA., 2017. Federal democratic republic of Ethiopia central statistical agency, agricultural sample survey, report on livestock and livestock holding characteristics. Central Statistical Agency, Addis Ababa, Ethiopia.

Cerqueira, J.O.L., J.P.P. Araujo, P.S. Vaz, J. Cantalapiedra and I. Blanco-Penedo et al., 2013. Relationship between zoometric measurements in Hosltein-Fresian cow and cubicle size in dairy farms. Int. J. Morphol., 31: 55-63.

Chamberlain, A., 2017. Identification of horned and polled bostaurus using a gene test. B.Sc. Thesis, Lincoln University, Lincoln, England.

Cherkoes, A.M. and Z. Mekuria, 2018. Factor affecting calving interval of dairy cows in central highlands of Ethiopia. J. Bio. Agric. Healthcare, 8: 71-74.

Dioli, M., 2018. Nomad aesthetic: Cattle modifications among the Northern Turkana of North West Kenya. Pastoralism, Vol. 8, 10.1186/s13570-017-0110-4

Eticha, B. and H. Disassa, 2017. Study on the prevalence of the major endo and ectoparasites of oxen in and around Debre Zeit Twon. Acta Parasitologica Globalis, 8: 17-25.

FAO., 2012. Phenotypic Characterization of Animal Genetic Resources. Vol. 11, Food and Agriculture Organization, Rome, Italy, ISBN: 9789251071991, Pages: 142.

FAO., 2018. Africa sustainable livestock Livestock production systems spotlight Cattle sectors in Ethiopia. Food and Agriculture Organization, Rome, Italy.
Fenetahun, Y., X. Xu and Y.D. Wang, 2019. Assessment of range land degradation, major causes, impacts and alternative rehabilitation techniques in Yabello Rangelands Southern Ethiopia. Review paper. Preprint. 10.20944/preprints201807.0198.v1

Garoma, S., 2006. In-situ phenotypic characterization of Kereyu cattle type in Fentalle district of Oromia region, Ethiopia. M.Sc. Thesis, Haramaya University, Haramaya, Ethiopia.

Garoma, S., W. Ayalew and P.B. Hegde, 2013. Pastoralists and agro-pastoralists preferences for cattle breed and traits in Fentalle district of East Shoa zone of Oromia, Ethiopia. Afr. J. Agric. Res., 8: 5645-5650.

Gebissa, D.T., 2014. Assessment of dairy cattle husbandry and breeding management practices of lowland and mid-highland agro-ecologies of Borana zone. J. Anim. Vet. Sci., 2: 62-69.

Gebrehiwot, T., 2017. Hides and skins production and marketing systems in Ethiopia; A systematic review (Des, 2017). Int. J. Eng. Dev. Res., 5: 1125-1128.

Gebreyohanes, M.F., 2015. Production system and phenotypic characterization of Begait cattle and effects of supplementation with concentrate feeds on milk yield and composition of Begait cows in Humera ranch, Western Tigray, Ethiopia. Ph.D. Thesis, Adiss Abeba University, Addis Abeba, Ethiopia.

Getinet, M., A. Workineh and P.B. Hegde, 2009. Growth and reproductive performance of Ogaden cattle at Haramaya University, Ethiopia. Ethiop. J. Anim. Prod., 9: 13-38.

Girmay, T. and Z. Teshome, 2017. Assessment of traditional medicinal plants used to treat human and livestock ailments and their threatening factors in gulomekeda district, Northern Ethiopia. Int. J. Emerg Trends Sci. Technol., 4: 5061-5070.

Kebede, H., A. Jimma, A. Getiso and B. Zelke, 2017. Characterization of Gofa Cattle population, production system, production and reproduction performance in Southern Ethiopia. J. Fish. Livest Prod., Vol. 5, No. 5. 10.4172/2332-2608.1000237

Khatri, N. and S. Tyagi, 2015. Influences of natural and anthropogenic factors on surface and groundwater quality in rural and urban areas. Front. Life Sci., 8: 23-39.

Kugonza, D.R., M. Nabasirye, D. Mpairwe, O. Hanotte and A.M. Okeyo, 2011. Productivity and morphology of Ankole cattle in three livestock production systems in Uganda. Anim. Genet. Resour., 48: 13-22.

Laske, C.H., B.B.M. Teixeira, N.J.L. Dionello and F.F. Cardoso, 2012. Breeding objectives and economic values for traits of low input family-based beef cattle production system in the State of Rio Grande do Sul. Rev. Bras. Zootecnia, 41: 298-305. 
Legesse, D., 2016. Assessment of breeding practice and evaluation of estrus synchronization of dairy cattle in Sidama Zone, Southern Ethiopia. M.Sc. Thesis, Hawassa University, Hawassa, Ethiopia.

Li, X.L., J. Gao, G. Brierley, Y.M. Qiao, J. Zhang and Y.W. Yang, 2011. Rangeland degradation on the qinghai-tibet plateau: Implications for rehabilitation. Land Degrad. Dev., 22: 193-201.

Makkar, H.P.S., A. Emily and G. Lemma, 2018. Characterization of feeding systems in Ethiopia with a focus on dry areas. Feedipedia Broadening Horiz., Vol. 51,

Mathews Jr, K.H. and S.D. Short, 2001. The beef cow replacement decision. J. Agribusiness, 19: 191-211.

Mekete, G., 2016. Studies on some morphological traits and structural indices of woyito-guji goats reared at Nyangatom and malleworedas of SNNPRS, Ethiopia. M.Sc. Thesis, College of Agriculture, Haramya University, Dire Dawa, Ethiopia.

Minuye, N., G. Abebe and T. Dessie, 2018. On-farm description and status of Nuer (Abigar) cattle breed in Gambella Regional State, Ethiopia. Int. J. Biodivers. Conserv., 10: 292-302.

Nazokkarmaher, M., 2016. The effect of inbreeding on Holstein-Friesian breed. M.Sc. Thesis, Animal, Dairy and Veterinary Sciences, Utah State University, Logan, Utah.

Negash, D., 2018. Review on dairy cow feed and feeding aspects in Ethiopia. CPQ. Nutr., 1: 01-19.

Olayemi, A.O., 2012. Effects of family size on household food security in Osun State, Nigeria. Asian J. Agric. Rural Dev., 2: 136-141.

Peters, K.J., P. Horst and H.H. Kleinheisterkamp, 1982. The importance of coat colour and coat type as indicators of productive adaptability of beef cattle in a subtropical environment. Trop. Anim. Prod., 7: 296-304.

Redda, T., 2001. Small-scale milk marketing and processing in Ethiopia. Proceedings of a South-South workshop held on National Dairy Development Board (NDDB'01), March 13-16, 2001, Anand, India, pp: 352-367.

Reta, A. and K. Abriham, 2018. Observational study of major dairy health problems in Ambo \& Holeta town, Oromia Region. East Afri. Scholars J. Agri. Life Sci., 1: 33-38.

Roberts, S.L., 2017. Effect of castration and oral meloxicam on inflammation, animal behavior and growth performance in beef cattle. Ph.D. Thesis, West Texas A\&M University, Canyon, Texas.

Solomon, T. and E. Hussen, 2018. Benefits of farm animals genetic adaptation: A review. J. Eur. Exp. Biol., Vol. 8, No. 4.

Tadege, A. and B. Afera, 2016. Assessment of vaccination coverage of sheep and goat using retrospective data in Woreda Raya Alamata. Momona Ethiopian J. Sci., 8: 83-88.
Taye, T., 2005. On-farm phenotypic characterization of Sheko breed of cattle and their habitat in Bench Maji Zone, Ethiopia. M.Sc. Thesis, Haramaya University, Haramaya, Ethiopia.

Terefe, E., T. Dessie, A. Haile, W. Mulatu and O. Mwai, 2010. Husbandry and breeding practices of cattle in Mursi and Bodi pastoral communities in Southwest Ethiopia. Afr. J. Agric. Res., 7: 5986-5994.

Terefe, E., T. Dessie, A. Haile, W. Mulatu and O. Mwai, 2015. On-farm phenotypic characterization of Mursi cattle in its production environment in South Omo Zone, Southwest Ethiopia. Anim. Genet. Resourc., 57: 15-24.

Tewelde, G., Y. Sintayehu and B. Sandip, 2017. Some morphometrical, production and reproduction traits of Begait cattle reared in Tigray region of Ethiopia. Wayamba J. Anim. Sci., 9: 1571-1585.

Tilahun, A., B. Teklu and D. Hoag, 2017. Challenges and contributions of crop production in agro-pastoral systems of Borana Plateau, Ethiopia. Pastoralism, Vol. 7, 10.1186/s13570-016-0074-9

Tonamo, A., B. Tamir, G. Goshu and E. Belete, 2015. Characterization of cattle husbandry practices in Essera Woreda, Dawuro Zone, Southern Ethiopia. Afr. J. Agric. Res., 10: 3421-3435.

Tulu, D., G. Mengistu, E. Yadessa, A. Bogale and M. Aleme, 2018. Study on major health problem of cattle development in mezhenger, sheka and benchi-maji zones of South Western Ethiopia. Acad. Res. J. Agri. Sci. Res., 6: 222-232.

Waktole, H., M. Almaw and D. Taweya, 2018. Opportunities and challenges of indigenous chicken in Asella district, Arsi zone, Oromia, Ethiopia: Implications for designing improved productivity schemes. J. Bacteriol Mycol. Open Access, 6: 229-235.

Watanabe, K., B. Lewis, T.B. Mlewah and M. Tetsuka, 2017. Age at first calving and factors influencing it in dairy heifers kept by smallholder farmers in Southern Malawi. Japan Agric. Res. Q. (JARQ.), 51: 357-362.

Wondossen, A., A. Mohammed and N. Enyew, 2018. Reproductive performance of Holstein friesian dairy cows in a tropical highland environment. J. Adv. Dairy Res., Vol. 6, 10.4172/2329-888X.1000203

Worku, B. and N. Lisanework, 2016. Pastoral perceptions towards livestock and rangeland management practices in Kuraz district of South Omo Zone, South Western Ethiopia. J. Nat. Sci. Res., 6: 60-69.

Worku, M., 2017. Assessment of type function and traditional selection practices of indigenous cattle reared in Shaka Zone South West Ethiopia. M.Sc. Thesis, College of Agriculture, Hawassa University, Ethiopa. 
Yosef, B.A. and D.K. Asmamaw, 2015. Rainwater harvesting: An option for dry land agriculture in arid and semi-arid Ethiopia. Int. J. Water Resour. Environ. Eng., 7: 17-28.

Zeleke, B. and M. Getachew, 2017. Traditional cattle husbandry practice in Gamo Gofa Zone, Southern Western Ethiopia. Int. J. Novel Res. Life Sci., 4: $1-7$.
Zeleke, B. and M. Melese, 2018. Assessment of traditional goat husbandry practices in Gamo Gofa Zone, Southwestern Ethiopia. Global Vet., 20: 11-18.

Zewdu, A., K. Alemayehu and Z. Wondifraw, 2018. Breeding practices and farmers trait preferences on indigenous dairy cattle production in East Gojjam Zone, Ethiopia. Asian J. Agric. Food Sci., Vo. 6, No. 1 . 